\title{
Environmentally sustainable health care: using an educational intervention to engage the public health medical workforce in Australia
}

\author{
Kate E. Charlesworth ${ }^{\mathrm{A}, \mathrm{E}}$, D. Lynne Madden ${ }^{\mathrm{B}}$ \\ and Anthony G. Capon ${ }^{\mathrm{C}, \mathrm{D}}$ \\ ${ }^{\mathrm{A}}$ NSW Public Health Officer Training Program, NSW Ministry \\ of Health \\ ${ }^{\mathrm{B}}$ School of Medicine, Sydney, The University of Notre Dame \\ (formerly Public Health Training and Workforce, Centre for \\ Epidemiology and Evidence NSW Ministry of Health) \\ ${ }^{\mathrm{C}}$ Faculty of Health, University of Canberra \\ ${ }^{\mathrm{D}}$ International Institute for Global Health, United Nations \\ University, Kuala Lumpur \\ ${ }^{\mathrm{E}}$ Corresponding author. Email: kate.charlesworth@gmail.com
}

\begin{abstract}
Awareness of the benefits of environmentally sustainable health care is growing. In the United Kingdom in 2010, an educational intervention on sustainable health care was successfully delivered to public health registrars. We conducted a feasibility study to test the intervention in Australia. Methods: The intervention consisted of a 1-day workshop delivered faceto-face covering climate change, sustainability and health. The workshop was modified, piloted and then delivered to 33 health professionals. Modifications included using Australian resources, introducing active learning exercises and including guest speakers. Delivery by videoconference was trialled. Outcomes were assessed in three areas - awareness, advocacy and action using questionnaires and follow-up telephone interviews. Results: There were improvements in participants' mean awareness and advocacy scores. All participants rated sustainability as 'important' for health professionals and many looked to their professional organisation to take a lead advocacy role on this issue. Discussion: This study demonstrated that the workshop is feasible for use in Australia; the modifications and delivery by videoconference were well received.
\end{abstract}

Provision of health care services is an energy intensive activity and the health sector is a major consumer of water, food, transport, pharmaceuticals, and other resources. ${ }^{1,2}$ In aggregate, these resources and related waste products are the 'ecological footprint' of health care services. Health professionals need to understand the importance of planetary health for the future health and wellbeing of people $e^{3,4}$ and work to ensure the delivery of sustainable forms of health care.

The health care sector would derive multiple benefits health, financial, reputational and environmental - from taking a lead on sustainability. Environmentally sustainable health care requires the transformation of the health care sector - a shift from expensive and carbon-intensive delivery (e.g. excessive use of pharmaceuticals and singleuse items) - towards more efficient use of resources and innovative models of care. Health professionals are central to both the design and delivery of health services and must advocate for, lead and help manage this transformation. Education about climate change and sustainability is slowly being incorporated into undergraduate health curricula, ${ }^{5}$ and strategies such as the recent NSW Health Environmental Sustainability Strategy ${ }^{6}$ should improve staff awareness of this issue. However, most health professionals have not been taught about sustainability and how they can both adapt their practice and support the health system to change.

In the United Kingdom (UK), the National Health Service (NHS) Sustainable Development Unit (www.sdu.nhs.uk) is tasked with assisting the NHS to become a leading low-carbon and sustainable health service. The Unit developed an educational intervention on sustainable health care and in 2010 delivered this to more than 200 UK Faculty of Public Health registrars, from both medical and non-medical backgrounds, through 15 workshops. ${ }^{7}$ The intervention consisted of a 4-hour workshop and, using a train-the-trainer approach, provided participants with resources and encouragement to run further workshops themselves. At the end of the workshop, the participants were asked to pledge to take action and a sample were followed up to determine what action they had taken and why.

The current study sought to determine whether a modified version of this intervention was suitable for an Australian 
public health medicine audience, including specialist postgraduate trainees and established practitioners.

\section{Methods}

Permission was sought from the NHS Sustainable Development Unit to use the intervention and the supporting resources. They agreed to provide free access on the condition that it remained free access and that adaptation and further implementation was evaluated.

\section{Literature review updated}

A literature review conducted in late 2009 exploring the education and training of health professionals in sustainable health care informed the original development of the intervention. This was updated in $2011^{8}$ through a search in PubMed using the terms 'climate change medical education', 'environmental sustainability medical education', 'climate change health education', 'climate change health professional development' and 'climate change health training'. As it was an update, the search was limited to the past 3 years and to English language papers $(n=106)$. Few papers of direct relevance were identified, and most of these were debate and discussion papers rather than presentations of original research. A number of the relevant papers were written by Australian authors, however these focused on the education of medical students as opposed to postgraduate training or the professional development of practitioners. Two papers called for doctors and health professionals to raise awareness and advocate on this issue. ${ }^{9,10}$

An additional search strategy used personal communication with colleagues engaged in the Sustainable Healthcare Education network (http://greenerhealthcare.org/ sustainable-healthcare-education).

\section{Updating the resources and adapting delivery}

The intervention materials, in particular the major resource of a PowerPoint slide bank of approximately 130 slides, were updated and tailored for Australian participants. For example, local publications and research findings describing the health consequences of climate change for the Australian population were included. The train-the-trainer format of the workshops was retained. To encourage active learning and reflection by participants, a verbal self-rating exercise was introduced at the beginning and repeated at the end of the workshop (Box 1). Situational interest was enhanced through invited guest speakers describing the action they have taken to create sustainability initiatives within their local health system. ${ }^{11}$ The workshop was piloted with 10 Fellows and Trainees of the Royal Australasian College of Physicians (RACP) working group on climate change and further refined on the basis of their feedback.

The final model consisted of a 4-5 hour workshop on climate change, sustainability and health. It was delivered

\section{Box 1. Self-ranking exercise}

Participants were asked to rank themselves on how confident they felt to advocate on the issue of climate change, sustainability and health using a scale of 0 to 10 , where 0 is not at all confident and 10 is extremely confident. Participants stood and positioned themselves along an imaginary line in the room and reflected with the group on how they ranked themselves.

This exercise was undertaken at the beginning of the workshop and then repeated again at the end, just before participants completed their evaluation forms.

face-to-face in three workshops held at the RACP Education Centre in Sydney in June 2011. For the final workshop, in addition to the face-to-face audience, a remote audience at seven sites around Australia was linked by videoconference.

\section{Evaluation}

To allow comparison of the results of the workshops held in the UK and Australia, the learning objectives were maintained and only minor changes made to the evaluation $\operatorname{method}^{7}$ (e.g. feedback was sought on the modifications made to the workshop's format and delivery).

As in the original study, outcomes in the areas of awareness, advocacy and action were assessed, and these acted as surrogate measures of knowledge, attitudes and practices. Levels of awareness and advocacy were measured using a questionnaire administered on arrival at the workshop (baseline) and again at the end of the workshop (post-intervention). The respondents self-rated their levels of awareness (10 statements) in relation to statements about climate change (basic science and health effects), sustainability, the carbon footprint of the NHS (the carbon footprint of the Australian health system has not been measured, however it is likely to be comparable to that of the UK), and the roles and responsibilities of health professionals using a four-point modified Likert scale (from 'not at all aware' to 'strongly aware'). They also rated their ability to advocate (10 statements) using a fourpoint Likert scale (from 'strongly disagree' to 'strongly agree'). The participants' baseline and post-intervention questionnaire scores were compared as pairs of matched questionnaires.

This study included, at the end of the questionnaire, two closed questions that explored the participants' perception of the importance of this issue to health professionals; one open-ended question that asked what role they would like their professional body to take on this issue; and three open-ended questions that sought their general feedback on the workshop. 
The action objective was evaluated by conducting telephone interviews 3 months after the intervention with a random sample of five participants (covering all three workshops). The interview consisted of 10 semi-structured questions and lasted approximately 30 minutes. Interviewees were asked whether and to what extent they had achieved their pledged actions; they were encouraged to speak freely about their experiences and their opinions on this issue. The responses were collated and a framework analysis conducted to identify the emerging themes. Both the interviews and analysis were conducted by the first author.

\section{Results}

Awareness and advocacy

Across the three workshops there were 33 participants; the majority were Fellows and Trainees of the Australasian Faculty of Public Health Medicine (AFPHM), the target audience, but there were also general practitioners and other medical specialists present. There were 23 completed, matched questionnaires (response rate: 70\%). Several people arrived late or left the workshop early and so did not complete both questionnaires, and some videoconference participants did not return their questionnaires.

The mean improvement in participants' self-reported levels of awareness was 11.1 points, and in advocacy was 9.1 points. Given that there were 10 awareness questions, with four possible Likert-scale responses, these results indicate that, on average, participants moved up one whole 'point' on the awareness scale on every question, as a result of the workshop. For example, in response to the question 'I could explain the basic science of climate change' the participant may have moved from 'disagree' to 'agree'. There were also 10 advocacy questions, and so the results for those were similar. Interestingly, these results are very similar to those documented in the UK in $2010 .^{7}$

As part of the advocacy objective, one of the aims of the project was for participants to subsequently facilitate a similar session themselves. Of the five participants followed up by telephone at 3 months, two had facilitated a session.

\section{The workshop: how to engage and challenge participants} Nearly all (97\%) participants rated the workshop as either 'extremely useful' or 'useful', with an even split between the two rankings. Participants cited the 'train-the-trainer' approach and the expectation of adopting an advocacy role and acting on this issue as being "empowering", for example: "[it is] our responsibility" to "take concrete action". The discussion topics that caught their attention were: the focus on sustainability rather than climate change; the per capita carbon footprints of countries (Australia's is amongst the highest in the world); and the realisation that climate change is an issue of social justice and health inequity. Framing the issue positively and focusing on the co-benefits for health were valued.

\section{Professional and public perceptions of sustainability}

When asked their opinion about sustainability, $82 \%$ of participants rated it as 'extremely important' for health professionals (with the remaining 18\% rating it as 'important'). In response to an open-ended question about what role participants would like their professional body (the RACP or AFPHM) to take on this issue almost every participant (93\%) answered and the majority (85\%) stated that they would like the College/Faculty to take a professional lead and/or adopt a public advocacy role on this issue.

\section{Reflection on pledged actions}

In reply to the question, 'To what extent have you achieved your actions?' three of the five people interviewed responded, 'somewhat'. The most common reasons for not achieving actions were lack of time, and being a newcomer and relatively junior at their workplace. These results were comparable with those from the UK study.

A clear difference with the UK responses was the comments regarding the public perception of climate change. Three of the five Australian interviewees commented upon the "poor level of discussion" in Australia about the carbon tax and climate change in general; one person noted that people advocating action on climate change are often regarded as "radical". To tackle this, interviewees suggested: focusing on sustainability (rather than climate change) and on the health co-benefits, and for support, forming an action group rather than acting as individuals.

\section{Videoconferencing the intervention}

Videoconferencing delivery was logistically and technically successful, and remote participants engaged well throughout the session. Remote participants were asked to scan and email their questionnaires to the facilitator however the response rate for this group was low. The feedback received, however, was positive.

\section{Discussion}

This study was limited by its small size, and in particular the small number of telephone interviews conducted. However, its objective was modest: to assess the feasibility of adapting a proven educational intervention to an Australian public health audience. The improvements in participants' awareness and advocacy scores, the fact that the workshops were well received, and participants' support for action on this issue, suggest that this is a feasible model for Australia. 
The modifications to the workshop helped to build an environment for active learning and reflection (selfranking exercise and the use of at least one local guest speaker as part of each workshop). These provided a source of situational interest to stimulate learning and motivate participants. ${ }^{11,12}$

The workshop is relevant to rural, remote and metropolitan health practitioners. To enable accessibility of the workshop for these health practitioners in Australia, the acceptability of videoconferencing as a mode of delivery is relevant. ${ }^{13}$

Many of the themes that emerged from the open-ended evaluation questions were similar to those in the UK study. ${ }^{7}$ Many of the differences appear to stem from a frustration among Australian participants about the lack of national political leadership for systematic change on this issue. There are different political and legislative contexts for action on climate change in the UK and Australia. In the UK, there is continuing bipartisan support for action, and the current Conservative-led Government pledged to be "the greenest government ever". ${ }^{14}$ The UK Climate Change Act $(2008)^{15}$ provided the impetus for the NHS carbon reduction targets and the health sector is required to report regularly to Parliament, along with all other sectors, on the success of carbon reduction strategies. The first of these reports was tabled this year. ${ }^{16}$ Meanwhile the NHS, the Department of Health (England), many of the medical colleges including the Royal College of Physicians and the Royal College of General Practitioners, the Faculty of Public Health, and leading medical journals such as the British Medical Journal and The Lancet, are championing this issue.

A supportive environment is developing in New South Wales. The State Government Sustainability Policy sets targets and strategies that include sustainability measures to reduce greenhouse gas emissions. ${ }^{17}$ Nationally, the work of the Climate Commission ${ }^{18}$ has supported evidenceinformed action, while the formation of the Climate and Health Alliance (http://caha.org.au/) creates a collective voice for health and public health organisations. The workshops described in this paper and supported by the AFPHM and the RACP contribute to both raising the awareness of public health professionals and encouraging them to advocate for change within their own workplaces. In order to affect widespread change in the health care system, other health professionals, including practicing clinicians, will need to become informed and active on this critical health issue.

\section{Conclusion}

Sustainability is a 'good news' story for health; it encompasses a focus on preventive care, healthier lifestyles, more efficient resource use and less waste, futures planning and innovative models of care and service delivery, including greater use of information communication technology. It represents an opportunity for health professionals to help to transform health care and the systems through which it is delivered. The workshops described in this paper have the potential to engage the public health workforce in Australia with the challenge of achieving environmentally sustainable health care.

\section{Acknowledgments}

The workshops described in this paper are based on a model initially developed by the National Health Service Sustainable Development Unit (www.sdu.nhs.uk) with financial support from the Department of Health (England) Public Health Leadership and Workforce stream.

The version described in this paper was adapted for an Australian public health audience by the Royal Australasian College of Physicians with financial support from the Australian Government Department of Health and Ageing through funding from the Public Health Education and Research Program.

The office of the Australasian Faculty of Public Health Medicine coordinated the delivery of the workshops described in this paper. The authors would like to thank Ms Susanne Englehard for her contribution to the success of this project.

\section{References}

1. Healthy Hospitals, Healthy Planet, Healthy People. Addressing climate change in health care settings [Discussion Draft]. World Health Organization \& Health Care Without Harm. Available at: http:/www.who.int/globalchange/publications/climatefootprint _report.pdf(Cited 5 August 2013).

2. Pencheon D, Rissel CE, Hadfield G, Madden DL. Health sector leadership in mitigating climate change: experience from the UK and NSW. N S W Public Health Bull 2009; 20(11-12): 173-6.

3. Boyden S. The Biology of Civilisation: Understanding Human Culture as a Force in Nature. Sydney: UNSW Press; 2004.

4. Rockström J, Steffen W, Noone K, Persson A, Chapin FS 3rd, Lambin EF et al. A safe operating space for humanity. Nature 2009; 461: 472-5. doi:10.1038/461472a

5. Barna S. Teaching Sustainable Healthcare in English Medical Schools Survey 2010 - Summary of Results. Sustainable Healthcare Education Network. Available at: http://greener healthcare.org/sustainable-healthcare-education/resources/ 2012/02/teaching-sustainable-healthcare-english-medical-s (Cited 5 August 2013).

6. Health Environmental Sustainability Strategy NSW. 2012 to 2015. Available at: http://www0.health.nsw.gov.au/pubs/2012/ pdf/env_sus_strat201215.pdf (Cited 29 August 2013).

7. Charlesworth KE, Ray S, Head F, Pencheon D. Developing an environmentally sustainable NHS: outcomes of implementing an educational intervention on sustainable health care with UK public health registrars. NS W Public Health Bull 2012; 23(1-2): 27-30. doi:10.1071/NB11018

8. Charlesworth K, Madden L, Capon A, Englehard S. Climate Change, Sustainability and Health - Workshops for Medical Professionals: Evaluation Report. July 2011, Australasian Faculty of Public Health Medicine. Available at: http://www.racp. edu.au/page/racp-faculties/australasian-faculty-of-publichealth-medicine/news-and-events/reports/ (Cited 5 August 2013). 
9. Green EI, Blashki G, Berry HL, Harley D, Horton G, Hall G. Preparing Australian medical students for climate change. Aust Fam Physician 2009; 38(9): 726-9.

10. Sarfaty M, Abouzaid S. The physician's response to climate change. Fam Med 2009; 41(5): 358-63.

11. Rotgans JI, Schmidt HG. Situational interest and academic achievement in the active-learning classroom. Learn Instr 2011; 21: 58-67. doi:10.1016/j.learninstruc.2009.11.001

12. Schraw G, Lehman S. Situational interest: a review of the literature and directions for future research. Educ Psychol Rev 2001; 13(1): 23-52. doi:10.1023/A:1009004801455

13. Tomlinson J, Munro A, Johnson R, Madden DL, Phillips R, McGregor D et al. How does tele-learning compare with other forms of education delivery? A systematic review of telelearning educational outcomes for health professionals. $N S W$ Public Health Bull 2013; 24(2): 70-5.

14. British Prime Minister David Cameron pledges that his government will be, "the greenest government ever" when speaking to civil servants at the Department of Energy and Climate Change, London, May 2010. Available at: http://www.guardian. co.uk/environment/2010/may/14/cameron-wants-greenestgovernment-ever (Cited 5 August 2013).

15. Climate Change Act 2008 (c.27), House of Lords Hansard Vol.705 Col.1477, House of Commons Hansard Vol.485 Col.855. London: HMSO (26 November 2008).

16. UK Climate Change Risk Assessment. Government Report. Department for Environment, Food and Rural Affairs (United Kingdom). London: The Stationery Office; January 2012. Available at: http://www.defra.gov.uk/publications/2012/01/26/ pb13698-climatechange-riskassessment/ (Cited 5 August 2013).

17. NSW Government Sustainability Policy. Department of Environment \& Climate Change NSW, 2008. Available at: http:// www.environment.nsw.gov.au/government/policy.htm (Cited 5 August 2013).

18. Hughes L, McMichael T. The Critical Decade: Climate Change and Health. Commonwealth of Australia (Department of Climate Change and Energy Efficiency), 2011. Available at: $\mathrm{http} / / /$ climatecommission.gov.au/wp-content/uploads/ 111129_FINAL-FOR-WEB.pdf (Cited 5 August 2013). 